\title{
Health impact of smoking - an unforgiveable omission in a doctor's repertoire
}

This article was published in the following Dove Press journal:

International Journal of General Medicine

14 May 2014

Number of times this article has been viewed

\section{Thomas I Lemon}

Institute of Medical Education, Cardiff University, Cardiff, UK
Correspondence: Thomas I Lemon Institute of Medical Education, Cardiff University, Cardiff CFI0 3XQ, UK Tel +44792728 8906 Email lemonti@doctors.org.uk

\section{Dear editor}

Rahman et $\mathrm{al}^{1}$ should be thanked for their discussion-provoking paper investigating the smoking behavior of patients and staff in a hospital based in Melbourne, Australia. The authors hoped to gather epidemiological data surrounding smoking, information on dependence to nicotine, and attitudes toward both the health impact and quitting strategies of smokers.

The authors decided to use a cross-sectional study design, limiting knowledge of the temporal outcome. This was further limited by a 2-hour time frame for data collection, meaning cohort inclusion was representative of a time of day rather than whole population. Data would be ideally collected over a week or month, for 24 hours each day to ensure adequate recruitment. The study would have been further reinforced by grouping of study participants, giving the reader further insight into smoking characteristics. The authors acknowledge smokers are less likely to have taken part in the study than non-smokers, also impacting on result reliability. This bias may even be more pronounced in health professionals due to potential embarrassment.

Limitations aside, this paper is of interest, with hospital staff less likely to smoke (7\% compared to $16 \%$ in general population). ${ }^{1}$ The paper raises a serious concern regarding the fact that hospital staff are not aware of the extent of smoking side effects. While this may include both medical staff and non-medical staff due to methodological oversight, it is concerning enough to warrant further attention and study. It also highlights the need for undergraduate education on smoking and for rigorous research skills, as without either of these, the problem identified will only continue. ${ }^{2}$ The authors should be thanked for raising this pertinent issue.

\section{Disclosure}

The author reports no conflicts of interest in this communication.

\section{References}

1. Rahman MA, Wilson AM, Sanders R, et al. Smoking behavior among patients and staff: a snapshot from a major metropolitan hospital in Melbourne, Australia. Int J Gen Med. 2014;7:79-87.

2. Lemon TI, Lampard R, Stone BA. Research skills for undergraduates: a must! Perspect Med Educ. 2013;2(3):174-175. 


\section{Authors' reply}

Muhammad Aziz Rahman
Andrew M Wilson
Rhonda Sanders $^{2-4}$
David Castle $^{2-4}$
Karen Daws $^{3}$
David R Thompson
Chantal F Ski ${ }^{2}$
Sarah Matthews
Christine Wright $^{2}$
Linda Worrall-Carter

'St Vincent's Centre for Nursing Research (SVCNR), Australian Catholic University, Melbourne, VIC, Australia; ${ }^{2}$ The Cardiovascular Research Centre (CvRC), Australian Catholic University, Melbourne, VIC, Australia; ${ }^{3}$ St Vincent's Hospital, Melbourne, VIC, Australia; ${ }^{4}$ The University of Melbourne, Melbourne, VIC, Australia

\section{Dear editor}

This cross-sectional study was undertaken as one of the awareness-raising activities conducted in the study hospital during the World Health Organization World No Tobacco Day and there was only a window of opportunity to collect data. ${ }^{1}$ We agree that having a longer time frame, including a representative sample of both patients and health care staff, and categorizing the professions involved, would have revealed further useful data but it was beyond the scope of the study and practical feasibility. We aimed to have a 'snap shot' of smoking behavior in a large metropolitan hospital. The cross- sectional study was deemed as anonymous (and therefore non-threatening), so people were happy to take part in it as there was no way of identifying them or of follow-up. It was designed with a view to providing pilot data and ascertaining if there was any cause for concern. This became evident in the results. The finding of lack of awareness among hospital staff, although not categorized, was alarming indeed. While Australia is considered as a pioneer in tobacco control and the hospitals are smoke-free, lack of awareness regarding health effects of smoking even among the non-medical staff working in the study hospital is not acceptable. We agree with Lemon regarding the need of undergraduate education to address this issue but raising awareness at professional workplaces to address knowledge gaps is also required. Most importantly, hospital policy needs to consider tobacco use as an important issue across the hospital, irrespective of admission departments and commencing from history taking until discharge of patients, following examples from New Zealand. ${ }^{2}$

\section{Disclosure}

The authors report no conflicts of interest in this communication.

\section{References}

1. Rahman MA, Wilson AM, Sanders R, et al. Smoking behavior among patients and staff: a snapshot from a major metropolitan hospital in Melbourne, Australia. Int J Gen Med. 2014;7:79-87.

2. Ministry of Health. Targeting Smokers: Better Help for Smokers to Quit. Wellington, New Zealand: Ministry of Health; 2011.

\section{Publish your work in this journal}

The International Journal of General Medicine is an international, peer-reviewed open-access journal that focuses on general and internal medicine, pathogenesis, epidemiology, diagnosis, monitoring and treatment protocols. The journal is characterized by the rapid reporting of reviews, original research and clinical studies across all disease areas.
A key focus is the elucidation of disease processes and management protocols resulting in improved outcomes for the patient. The manuscript management system is completely online and includes a very quick and fair peer-review system. Visit http://www.dovepress.com/ testimonials.php to read real quotes from published authors. 